\title{
Enfoques y límites del humorismo sobre discapacidad. Su verdadera cromática
}

\section{Approaches and limits of humorism about disability. Its true color}

\begin{abstract}
Resumen
Análisis del humor y el humorismo sobre discapacidad basado en el estudio del léxico, sentido y usos más frecuentes del discurso sobre discapacidad, factores a tener en cuenta para establecer dichos límites, el cambio de modelo humorístico en relación con la discapacidad, dentro y fuera del escenario, y la actual cromática del humor sobre discapacidad y su impacto mediático. El objetivo principal del estudio es ofrecer claves para comprender la importancia y el sentido del "humor discapacitado" a través del trabajo de campo y el análisis de los modelos humorísticos y la emergencia de estos en las redes sociales.
\end{abstract}

\section{Palabras clave}

Discapacidad, humor, humorismo, límites del humorismo, modelos humorísticos.

\begin{abstract}
Analysis of humor and humorism about disability based on the study of lexicon, sense and the most frequent uses of discourse about disability, key factors to be taken into account to set these limits, the change of humoristic pattern related to disability, both on and off the stage, and the current color of humor about disability and its media impact. The main objective of this research is to offer keys to understand the importance and the sense of "disabled humor" through field work and analysis of humoristic models and the outbreak of such models in social networks.
\end{abstract}

\section{Keywords}

Disability, humor, humorism, limits of humorism, humoristic models.

1. Grupo de Investigación de Lógica, Lenguaje e Información de la Universidad de Sevilla (GILLIUS | HUM-609). ORCID: 0000-0002-9446-9496.

\section{Jesús Portillo-Fernández ${ }^{1}$ <jeporfer@us.es>}

Universidad de Sevilla. España

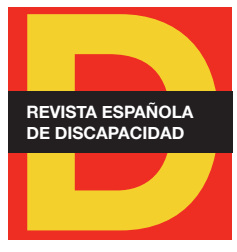

Para citar:

Portillo-Fernández, J. (2018):

"Enfoques y límites del humorismo sobre discapacidad. Su verdadera cromática". Revista Española de Discapacidad, 6 (II): 173-187.

Doi: <https://doi.org/10.5569/23405104.06.02.09>

Fecha de recepción: 07-11-2017 Fecha de aceptación: 17-05-2018

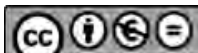




\section{Introducción}

La presente investigación aborda el tema de los límites del humorismo sobre discapacidad desde varias perspectivas: 1) el estudio del léxico, el sentido y los usos más frecuentes del discurso sobre discapacidad, 2) el análisis de los factores a tener en cuenta para establecer dichos límites, 3) el cambio de modelo humorístico, dentro y fuera del escenario, en relación con la discapacidad y 4) la actual cromática del humor sobre discapacidad y su impacto mediático.

En primer lugar, analizaremos los factores que influyen en el sentido del discurso sobre discapacidad, como el grado de relación con la discapacidad, el contexto comunicativo en el que se lleva a cabo dicho humorismo y la intención comunicativa de los emisores de este. Presentaremos un breve análisis contrastivo del significado / uso / sentido de los términos relacionados con la discapacidad en idiomas geográficamente cercanos al español, como propuesta de futuros estudios al respecto. En segundo lugar, revisaremos la definición y la relación habitual entre los términos «humor» $\mathrm{y}$ «humorismo» para comprender realmente qué ocurre en lo que denominamos «humor discapacitado». A partir de ahí, analizaremos los diferentes enfoques del humorismo relacionados con la discapacidad: humorismo relacionado con la discapacidad procedente de personas con discapacidad, procedente de personas sin discapacidad o de personas que no tienen vinculación directa con la discapacidad y procedente de personas sin discapacidad que tienen vinculación directa con la discapacidad.

Repararemos en la importancia del contexto comunicativo y los medios de difusión en los que, y a través de los cuales, se produce y difunde el humorismo sobre discapacidad. Revisaremos las limitaciones tradicionales y actuales, que han cambiado, y analizaremos el cambio de paradigma humorístico: del espectáculo de chistes sobre personas con discapacidad al humor monologado basado en supuestas experiencias propias. A partir del estudio de las características del actual $H D D$, nos centraremos en la proliferación de plataformas de difusión de «humor discapacitado» en redes sociales. Y, por último, a través de ejemplos mediáticos sobre $H D D$ exitoso y estudios sobre revistas satíricas que refuerzan las investigaciones ya realizadas sobre el humor como catalizador de emociones negativas, defenderemos la descatalogación de este tipo de humorismo como humor negro.

El principal objetivo del estudio es ofrecer las claves necesarias para comprender un fenómeno tan significativo como es el humorismo en el colectivo de personas con discapacidad, las repercusiones que tiene en la sociedad en general, sus bondades terapéuticas en el practicante / afectado y las limitaciones del humorismo dependientes de los factores analizados.

\section{Léxico, sentido y usos más frecuentes del discurso sobre discapacidad}

En la actualidad, el término más apropiado, políticamente correcto e institucionalizado para hacer mención a este colectivo es «personas con discapacidad». En el Real Decreto 1856/2009, de 4 de diciembre, de procedimiento para el reconocimiento, declaración y calificación del grado de discapacidad, que modifica el Real 
Decreto 1971/1999, de 23 de diciembre, en su «Disposición adicional segunda. Actualización terminológica y conceptual» y en consonancia con lo establecido en la disposición adicional octava de la Ley 39/2006, de 14 de diciembre, de Promoción de la Autonomía Personal y Atención a las personas en situación de dependencia y en la nueva clasificación de la Organización Mundial de la Salud, "Clasificación Internacional de Funcionamiento, de la Discapacidad y de la Salud» (CIF-2001); quedaron oficialmente sustituidos los términos "minusválidos" y "personas con minusvalía" por "personas con discapacidad".

Sin embargo, ya en 2005, el Foro de Vida Independiente y Divertad" propuso la expresión "mujeres y hombres con diversidad funcional" como una alternativa no peyorativa a "minusválido", "discapacitado", etc., que rechaza la tradicional visión del modelo médico de la diversidad funcional en la que se presentaba a la persona diferente como una persona biológicamente imperfecta que había que rehabilitar y "arreglar" para restaurar unos teóricos patrones de "normalidad" que nunca han existido, que no existen y que en el futuro es poco probable que existan precisamente debido a los avances médicos (Romañach y Lobato, 2005).

El Diccionario de la lengua española presenta la palabra discapacitado como un calco del inglés "disabled» y su etimología latina (dis- | capacitas / -atis) refiere la falta de capacidad para realizar alguna actividad. Gracias al calado de la educación en valores, a la visibilidad de este colectivo en medios de comunicación, a los planes estatales de ayuda e integración, a las asociaciones de afectados y familiares, así como a la mayor apertura y movilidad social, las expresiones relacionadas con la discapacidad han evolucionado. Personas encargadas de la coordinación de libros de estilo periodísticos como Álex Grijelmo, en el caso de El País, advertía que la obsolescencia de algunos términos utilizados para designar a ciertos colectivos crea lo que Bolinger (1980: 74) denominó "efecto dominó". El término discapacitado fue el recomendado en su día para sustituir a incapacitado físico o disminuido físico, que a su vez tuvieron como misión desplazar a minusválido (Galán, 2017).

Tradicionalmente, se han utilizado palabras y expresiones relacionadas con la discapacidad (analizadas posteriormente) que, dependiendo de quién las dijera y en el contexto en que se hiciera, podrían ser descriptivas o despectivas (insultos o descalificativos). El preámbulo de la Convención sobre los derechos de las personas con discapacidad (ONU, 2016) aprobado y ratificado por el Estado español, reconoce que la discapacidad es un concepto que evoluciona y que resulta de la interacción entre las personas con deficiencias y las barreras debidas a la actitud y al entorno que evitan su participación plena y efectiva en la sociedad, en igualdad de condiciones con las demás.

Las personas con discapacidad constituyen un sector de población heterogéneo, cuyas desventajas tienen su origen en las dificultades personales, pero especialmente en las condiciones limitativas y los obstáculos de la sociedad, en relación con la participación del resto de la población sin discapacidad. En el artículo 4 del Real Decreto Legislativo 1/2013, de 29 de noviembre, por el que se aprueba el Texto refundido de la Ley General de derechos de las personas con discapacidad y su inclusión social, se considera que las personas con discapacidad son aquellas que presentan deficiencias físicas, mentales, intelectuales o sensoriales, previsiblemente permanentes que, al interactuar con diversas barreras, puedan impedir su participación plena y efectiva en la sociedad, en igualdad de condiciones con los demás. De este modo, se distinguen cuatro tipos de discapacidad ${ }^{3}$ : física (falta, deterioro o alteración funcional de una o más partes del cuerpo, y que provo-

2. Véase : <http://forovidaindependiente.org/>.

3. A esta clasificación, atendiendo a los baremos utilizados en los centros de valoración, hay que añadir la distinción y relación de las enfermedades mentales y patologías neurodegenerativas, entre otras, con la discapacidad mental e intelectual (Real Decreto Legislativo 1/2013, de 29 de noviembre, por el que se aprueba el Texto Refundido de la Ley General de derechos de las personas con discapacidad y de su inclusión social). 
que inmovilidad o disminución de movilidad), sensorial (falta, deterioro o alteración de uno o más sentidos, dividida en auditiva -sordera parcial o total, dificultades para hablar- y visual -visión disminuida, ceguera-), intelectual (limitaciones significativas en el funcionamiento intelectual y en la conducta adaptativa, que se manifiesta en habilidades adaptativas conceptuales, sociales y prácticas) y mental (alteraciones o deficiencias en las funciones mentales, específicamente en el pensar, sentir y relacionarse. También conocido bajo el término de "discapacidad psicosocial").

La lengua española en las últimas décadas ha experimentado un proceso de edulcoración con relación al mundo de la discapacidad. La progresiva sensibilización de las nuevas generaciones ha propiciado la aparición de expresiones corteses o políticamente correctas para hacer mención a personas con discapacidad de cualquier índole. Los calificativos usados antes de este proceso, no solo tenían carácter peyorativo (desfavorable) y despectivo (menosprecio), sino que también de forma general se usaban como insultos a personas que no tenían discapacidad. Esto sigue sucediendo, pero cada vez menos, al considerarse inadecuadas, groseras y políticamente incorrectas para ser utilizadas en público.

En primer lugar, repararemos en los tres factores enunciados anteriormente que influyen en el significado y en el sentido real, para la comunidad hablante, de las palabras utilizadas en emisiones humorísticas: la intencionalidad del emisor, la relación con la discapacidad que tenga este y el contexto comunicativo en el que se usen.

- Dependiendo del grado de relación que el emisor tenga con la discapacidad se permitirán licencias, desde un punto de vista léxico-semántico, al hablar del tema. Normalmente, el nivel de implicación, cercanía psicológica y empatía con el colectivo es mayor en amigos y familiares de personas con discapacidad. Sin embargo, es habitual el desarrollo del humor negro en personas con discapacidad que hablan de discapacidad con el objetivo de relativizar y normalizar su situación.

- El contexto comunicativo, también determinado principalmente por el grado de relación con la discapacidad, estará influido por la postura que se adopte frente a la discapacidad y la empatía que los interlocutores tengan con este colectivo. Es decisiva la presencia o ausencia de personas con discapacidad en la conversación, así como la afectación directa del tema debatido. Obras de referencia como las de Brown y Yule (1993), Fuentes (2000) o Van Dijk (1980, 2000) analizan la importancia del contexto comunicativo en la construcción del sentido del mensaje, cómo determina su uso y la relación que guarda con los otros elementos del acto de comunicación. En nuestro caso, los temas más controvertidos suelen ser las ayudas sociales que las personas con discapacidad reciben, las barreras arquitectónicas del medio, la falta de equidad y su repercusión en el acceso y adaptación formativa, así como la invisibilización de algunos de estos problemas en los medios.

- Como en cualquier situación comunicativa, la intención comunicativa orienta la finalidad del discurso e igual que en otros temas sociales tiende a polarizarse. Sin embargo, debido a la fuerte presión social contra aquellos que no apoyan a las personas con discapacidad y los detractores de cualquier tipo de ayuda a favor de estas, argumentan habitualmente en grupos sabidos afines o de manera anónima.

Entre los términos despectivos utilizados en español destacan «inválido», «bardado», «lisiado» y «tullido» para referir discapacidad física y «majara», «mongolo», «retrasado» y «tarado» para mencionar discapacidad intelectual o mental, entre otros. Algunas de estas palabras relacionadas con la discapacidad, afortunadamente en desuso en el ámbito público, tienen su equivalencia en idiomas geográficamente cercanos al español. Sin embargo, otros no son traducibles, bien por tratarse de dialectalismos o localismos, bien por no considerarse necesarios o no haber 
evolucionado semánticamente la lengua en ese aspecto. En la Figura 1. Tabla Multilingüe sobre Discapacidad ${ }^{4}$ podemos observar que el mismo término, desde un punto de vista pragmático, no se considera igualmente apropiado aunque posea un contenido semántico equivalente en relación a otros idiomas. Las variaciones semánticas dependientes del contexto y los acuerdos de uso de la comunidad hablante reflejan diferentes formas de abordar lingüísticamente el tema de la discapacidad. Pero más allá de las diferencias de uso y significado, reconocemos la importancia de la institucionalización del léxico y la oscilación entre cortés o descortés de estos términos.

\begin{tabular}{|c|c|c|c|c|c|c|c|c|c|c|c|c|c|c|c|c|}
\hline \multicolumn{17}{|c|}{ Figura 1. Tabla multilingüe sobre discapacidad } \\
\hline & \multicolumn{2}{|l|}{ ESPAÑOL } & \multicolumn{2}{|l|}{ ALEMÁN } & \multicolumn{2}{|l|}{ ÁRABE } & \multicolumn{2}{|c|}{ FRANCÉS } & \multicolumn{2}{|l|}{ GRIEGO } & \multicolumn{2}{|l|}{ INGLÉS } & \multicolumn{2}{|l|}{ ITALIANO } & \multicolumn{2}{|c|}{ PORTUGUÉS } \\
\hline \multirow{3}{*}{$\begin{array}{l}\mathbb{8} \\
\frac{0}{0} \\
\frac{0}{6} \\
\frac{0}{\pi} \\
\frac{\pi}{0} \\
\frac{0}{0} \\
\frac{0}{0} \\
.0\end{array}$} & Bardado & D & $\mathrm{x}$ & & $\mathrm{x}$ & & Légume & D & $\begin{array}{l}\text { Avánnpoc } \\
\text { /Anápiros/ }\end{array}$ & C & $\mathrm{x}$ & & $x$ & & $\mathrm{x}$ & \\
\hline & Lisiado & D & Krüppel & D & 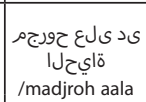 & D & Estropié & C & $\begin{array}{l}\text { Eakátnç } \\
\text { /Sakátis/ }\end{array}$ & D & Crippled & D & Storpio & D & $\begin{array}{l}\text { Aleijado } \\
\text { / Coxo / } \\
\text { Maneta }\end{array}$ & $\begin{array}{l}\text { TD } \\
i\end{array}$ \\
\hline & Tullido & $\begin{array}{l}\text { D } \\
\text { i }\end{array}$ & Krüppel & $\begin{array}{l}\text { D } \\
\text { i }\end{array}$ & 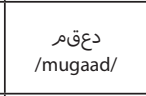 & D & Estropié & C & $\begin{array}{l}\text { Avárnpoç } \\
\text { /Anápiros/ }\end{array}$ & C & Lame & D & Storpio & $\begin{array}{l}\text { D } \\
\text { i }\end{array}$ & $\begin{array}{l}\text { Aleijado / } \\
\text { Paralítico }\end{array}$ & $\mathrm{D}$ \\
\hline \multirow{5}{*}{ 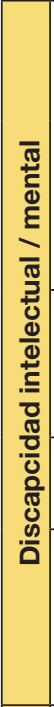 } & \multirow[b]{2}{*}{$\begin{array}{l}\text { Majara / } \\
\text { Majareta }\end{array}$} & \multirow[b]{2}{*}{ D } & \multirow[b]{2}{*}{ Geisteskrank } & \multirow[b]{2}{*}{$\begin{array}{l}\text { D } \\
\text { i }\end{array}$} & \multirow[b]{2}{*}{$\begin{array}{l}\text { ofigo } \\
\text { /matuh/ }\end{array}$} & \multirow[b]{2}{*}{ D } & \multirow[b]{2}{*}{$\begin{array}{l}\text { Débile / } \\
\text { Taré }\end{array}$} & \multirow[b]{2}{*}{ D } & 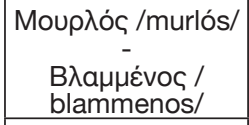 & D & \multirow[b]{2}{*}{$\begin{array}{c}\text { Batty / Nuts / } \\
\text { Mad }\end{array}$} & \multirow[b]{2}{*}{ D } & \multirow[b]{2}{*}{$\begin{array}{l}\text { Matto / } \\
\text { Suonato / } \\
\text { Impazzito }\end{array}$} & \multirow[b]{2}{*}{$\begin{array}{l}\text { D } \\
\text { i }\end{array}$} & \multirow[b]{2}{*}{$\begin{array}{l}\text { Maluco / } \\
\text { Luoco }\end{array}$} & \multirow[b]{2}{*}{$\mathrm{D}$} \\
\hline & & & & & & & & & 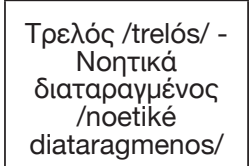 & C & & & & & & \\
\hline & Mongolo & D & Mongo & $\begin{array}{l}\mathrm{D} \\
\dot{ } \\
\dot{\mathrm{I}} \\
\mathrm{TD}\end{array}$ & $\begin{array}{l}\text { /mangoli// } \\
\text { /mang }\end{array}$ & D & Mongole & D & 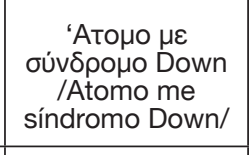 & C & $\begin{array}{l}\text { Retarded / } \\
\text { Moronic }\end{array}$ & D & Mongoloide & D & Mongolóide & $\begin{array}{l}\text { D } \\
\text { i }\end{array}$ \\
\hline & Retrasado & $\begin{array}{l}\mathrm{D} \\
\mathrm{i}\end{array}$ & $\begin{array}{c}\text { geistig } \\
\text { zurückgeblieben }\end{array}$ & $\begin{array}{l}\text { D } \\
\text { i }\end{array}$ & 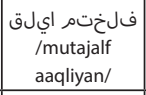 & $\begin{array}{l}\text { D } \\
\text { i }\end{array}$ & Retardé & D & 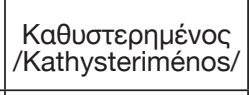 & C & Retarded & D & $\begin{array}{l}\text { Ritardato } \\
\text { (mentale) }\end{array}$ & D & $\begin{array}{c}\text { Atrasado } \\
\text { mental }\end{array}$ & $\begin{array}{l}\mathrm{B} \\
\mathrm{i}\end{array}$ \\
\hline & Tarado & D & Bescheuert & 1 & $\begin{array}{l}\text { squ } \\
\text { /maiyb/ }\end{array}$ & $\begin{array}{l}\text { D } \\
\text { I }\end{array}$ & $\begin{array}{l}\text { Taré / Idiot } \\
\text { / Imbécile }\end{array}$ & D & 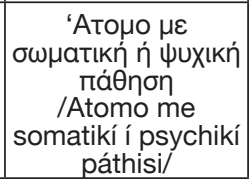 & C & $\begin{array}{l}\text { Barmy / Off } \\
\text { his rocker }\end{array}$ & D & $\begin{array}{l}\text { Scemo / } \\
\text { Sciocco }\end{array}$ & D & $\begin{array}{l}\text { Luoco / } \\
\text { Tarado }\end{array}$ & $\stackrel{\mathrm{D}}{\mathrm{i}}$ \\
\hline $\mid \begin{array}{l}0 \\
0 \\
0 \\
\frac{0}{\varepsilon} \\
\frac{\varepsilon}{\alpha}\end{array}$ & Minusválido & $\begin{array}{c}\text { C } \\
\text { TD } \\
\end{array}$ & Behindert & C & $\begin{array}{l}\text { قاعl } \\
\text { /muaq/ }\end{array}$ & $\begin{array}{l}\text { D } \\
\text { I }\end{array}$ & Handicapé & C & $\begin{array}{l}\text { Me avannpía } \\
\text { /Me anapiría/ }\end{array}$ & C & Handycapped & C & Disabile & C & $\begin{array}{c}\text { Minusválido / } \\
\text { Deficiente }\end{array}$ & $\begin{array}{c}\text { C } \\
\text { TD }\end{array}$ \\
\hline
\end{tabular}

$\mathrm{C}=$ Cortés / Políticamente correcto $\mid \mathrm{D}=$ Descortés / Políticamente incorrecto $\mid \mathrm{TD}=$ Tendencia al desuso en ámbito público $\mid \mathrm{I}=$ También usado como insulto dependiendo del contexto.

Fuente: elaboración propia.

4. Tabla elaborada a partir de una pequeña muestra de términos españoles relacionados con la discapacidad gracias a la ayuda de filólogos nativos de cada lengua, con alto nivel de español. Se presenta como recurso ilustrador, no como síntesis de un estudio concluso. 
Palabras como «minusválido», considerada aún políticamente correcta por gran parte de la comunidad hablante y utilizada en señalética pública en español, a pesar de haberse sustituido oficialmente por "personas con discapacidad"; en árabe por ejemplo es descortés y puede utilizarse como insulto. «Inválido", que en español, árabe, italiano y portugués es un término por lo general descortés y puede utilizarse como insulto; en alemán, francés, griego e inglés se considera cortés. Sería interesante realizar en el futuro dos estudios sobre discapacidad: uno diacrónico en español y otro contrastivo multilingüe más amplio (en cantidad) y profundo (especificando contextos y significados) que pusiera de relieve las similitudes y diferencias en el lenguaje sobre discapacidad. Ilustramos esta comparativa para justificar el lugar que ocupa el humor en la modificación y el enriquecimiento semánticos del vocabulario de un ámbito, flexibilizando el uso de las palabras, generando neologismos o realizando préstamos lingüísticos.

\section{Factores a tener en cuenta para establecer los límites del humorismo sobre discapacidad}

Como afirma Siruana (2014) en su estudio sobre la ética del humor, tendremos que afrontar el conflicto entre proteger la libertad de expresión y proteger a aquellos que puedan ser víctimas de su mal uso, y precisamente, las personas con discapacidad pueden ser un colectivo potencialmente afectado.

A pesar de que el intento de definir el humorismo es como pretender atravesar una mariposa usando a manera de alfiler un poste telegráfico, como decía Jardiel Poncela en «Los españolitos y el humor» (Acevedo, 1972); la relación entre humor y ética es un tema en constante revisión que depende de la evolución educativa generacional y de la progresiva toma de conciencia del impacto negativo que puede tener. Del mismo modo, la psicología lleva décadas estudiando la importancia del humor, sus beneficios y su capacidad de transformar la percepción de la realidad. Obras de referencia como las de Garanto Alós (1983) y Martin (2008), e investigaciones como las de Carbelo y Jáuregui (2006), Chazenbalk (2006), Jáuregui (2008) o Barragán y Morales (2014), entre otras; analizan la psicología del humor, las formas y estilos, su valor psicoterapéutico y su vinculación con las emociones positivas. En nuestro estudio comenzaremos por aclarar los conceptos «humor» y «humorismo» con el objetivo de comprender cómo funcionan los agentes comunicativos y qué efectos tiene el humor sobre discapacidad en ellos, dependiendo de la posición que estos ocupen.

El (buen) humor es una condición, es la jovialidad, la capacidad de reírse de uno mismo e incluso de las desgracias. El humorismo, por su parte, es un modo de presentar, enjuiciar o comentar la realidad destacando el lado cómico, risueño o ridículo de las cosas. El humor es una disposición interna, un modo de percibir y vivir la realidad; mientras que el humorismo es la representación de la realidad que presentamos a los demás con la intención de hacer gracia.

Humor y humorismo no siempre se dan juntos, ni en todos los casos hay una relación causal entre ellos. Sin embargo, al analizar el sentido del humor en la discapacidad debemos prestar atención a los grados de relación con esta, que generan tres enfoques del fenómeno: 
1. El humorismo relacionado con la discapacidad, procedente de personas con discapacidad - $[H D D]$.

2. El humorismo relacionado con la discapacidad, procedente de personas sin discapacidad o de personas que no tienen vinculación directa con la discapacidad (familiares o amigos íntimos con discapacidad) - [HDnD].

3. El humorismo relacionado con la discapacidad, procedente de personas sin discapacidad que tienen vinculación directa con la discapacidad (familiares o amigos íntimos con discapacidad) - [HDvD].

El HDD se basa en la voluntad que tienen las personas con discapacidad de representar su realidad con sentido del humor, parodiando y destacando el lado cómico de las circunstancias que les toca vivir. Este tipo de humorismo es el que mayor tolerancia tiene en la comunidad hablante, ya que en él coinciden el humorista y el objetivo de este. El HDD suele entenderse como humor negro hecho por personas con discapacidad para personas con discapacidad, no teniendo prácticamente límites morales porque, precisamente, la eliminación de estos límites es lo que confiere a esta representación ontológica la capacidad de ridiculizar la gravedad de la discapacidad y sus efectos. Dicho de un modo sencillo, en estos casos humor y humorismo coinciden y tienen como objetivo ofrecer(se) una posición emocional superadora. Estudios como el de Rodríguez Idígoras (2002) o el de Carbelo (2008) ya avalaban hace más de una década el valor terapéutico del humor y la importancia del humorismo en la praxis médica hacia el paciente.

Por otro lado, el $H D n D$ se apoya en el mismo principio que el $H D D$, representar humorísticamente la realidad de las personas con discapacidad, pero al no tener discapacidad el emisor/artífice del mensaje existen reservas intencionales e interpretativas al respecto. Estos casos, por lo general, no suelen entenderse como humorismo (representación cómica) ni como humor (condición jovial), sino que se le atribuyen connotaciones sarcásticas. Habitualmente, la comunidad hablante considera inadecuado, descortés e incluso ofensivo que alguien sin discapacidad bromee sobre esta compleja realidad.

El punto intermedio entre los extremos comentados lo encontramos en el HDvD, un humorismo medianamente tolerado, vinculado al tipo y al grado de discapacidad que la persona cercana al emisor tenga y limitado por el contexto comunicativo en el que se diga. Por ejemplo, cuando una persona sin discapacidad que tiene un familiar o amigo íntimo con discapacidad bromea sobre discapacidad, con el consentimiento tácito del afectado por el problema, no se interpreta del mismo modo que cuando no está presente. Sucede algo parecido cuando esta persona bromea sobre discapacidad a otra persona que también tiene un familiar o amigo con discapacidad, ya que los niveles de tolerancia al humorismo son relativos al estado en que se encuentre la persona afectada.

Otro factor a tener en cuenta a la hora de comprender los límites del humorismo sobre discapacidad es el contexto comunicativo, en sentido estricto. Como sucede en cualquier situación comunicativa, el lugar en el que se produce la parodia es significativo para el modo en que la comunidad hablante interpreta el humorismo. Algunos escenarios relacionados con la discapacidad están cargados de connotaciones emocionales: hospitales, gimnasios de rehabilitación, localizaciones de accidentes, etc. El hecho de parodiar sobre estas ubicaciones es un límite prácticamente infranqueable debido a ser lugares comunes en los que se vive a diario la tragedia, el mantenimiento y la superación. No suele contemplarse la posibilidad de representar cómicamente estos escenarios vinculados al dolor emocional y físico, ya que incluso el HDD no estaría acreditado moralmente para hacer chistes sobre la desgracia ajena. 
Del mismo modo sucede con el momento en el que se parodia sobre discapacidad. Es evidente que uno de los factores más relevantes para producir una reacción humorística es el cálculo de la oportunidad de la broma, vinculado directamente con el estado de ánimo de las personas potencialmente afectadas por esta. El caso del $H D D$ no presenta limitaciones, ya que es la persona afectada quien bromea al respecto, habiendo escogido el momento que considera oportuno para relativizar el problema y hacerse fuerte frente a él. Sin embargo, en situaciones de $H D n D$ e incluso de $H D v D$ la inoportunidad es recurrente por la alta posibilidad de no escoger el momento adecuado.

Por último, quisiéramos reparar sobre el medio de difusión utilizado para expresar el humorismo relacionado con la discapacidad. Los denominados medios de comunicación de masas (Mass Media) son valiosísimas herramientas para hacer llegar la información a un elevado número de personas, en tiempo real y simultáneamente. Las producciones cinematográficas, las emisiones de televisión y radio (tanto informativas como de entretenimiento), las publicaciones de prensa digital o impresa, las redes sociales y las plataformas de comunicación móvil tienen la capacidad de transformar el modo de interpretar la realidad de la comunidad hablante. La difusión de información en estos medios tiene el poder de crear costumbre, habitualidad y "normalidad".

\section{Cambio del modelo humorístico en relación con la discapacidad, dentro y fuera del escenario}

Resulta llamativo comparar la extensa bibliografía dedicada al estudio del humor en general con la minúscula proporción que analiza el humor / humorismo sobre discapacidad. Parte de culpa la tiene la propia visión que la sociedad adopta sobre algunos temas, convertidos en tabúes por la incapacidad de normalizar estados o situaciones que se consideran anormales. Entonces, se produce el curioso efecto contrario, en lugar de preservar y proteger a las personas que tienen ese problema, las terminan estigmatizando socialmente.

Uno de los casos más significativos en cuanto a humorismo y discapacidad es el modelo humorístico español utilizado en la segunda mitad de siglo XX y principios del XXI: el espectáculo del chiste sobre personas con discapacidad. Sin duda, uno de los géneros humorísticos que más se ha aplaudido ha sido el chiste teatralizado sobre gangosos, jorobados, mudos, tartamudos, desequilibrados mentales, etc. Figuras como Arévalo (Francisco Rodríguez), Cassen (Casto Sendra), Eugenio (Eugenio Jofra), Félix el Gato (Félix Extremeño) o Gila (Miguel Gila), entre otros, basaban parte de su espectáculo humorístico en historias cómicas sobre personas con discapacidad.

Paulatinamente, en España, ha ido desapareciendo este tipo de humor negro que tenía como objeto los defectos físicos, intelectuales, mentales o sensoriales, dando paso a un humor monologado en primera persona basado en supuestas experiencias propias. El ya añejo $H D n D$ ha quedado obsoleto dando el relevo a un nuevo modelo humorístico $H D D$ y $H D v D$ sensible y compatible con la discapacidad. La obra «Mirando a la discapacidad con humor» (Jordán de Urríes y Verdugo, 2015) reunió un numeroso elenco de humoristas gráficos en un proyecto que trata de transformar la percepción social sobre discapacidad basada en el dolor, el sufrimiento y la limitación, por otra fundamentada en la relativización, la eliminación de prejuicios y la canalización de emociones. 
En el humorismo como mecanismo paliativo del dolor físico, la reducción de movilidad y las secuelas emocionales que conllevan, procedentes de la discapacidad, la enfermedad o de ambas, destacan las siguientes características:

- Debilitamiento del problema a través de la parodia y la ridiculización.

Hoy me he levantado con un dolorcito en el dedo índice, que no se me quita (persona con dolor crónico en la parte no amputada de un brazo). Pues no que se me han quedado dormidas las piernas, de estar en la misma postura (persona en silla de ruedas afectada de paraplejia). Perdona, no me he dado cuenta, no te he visto llegar (persona invidente), etc.

- Frecuente personificación de la enfermedad y/o discapacidad para poder insultarla y echarse apuestas con ella.

Se cree que va a poder conmigo, pero le va a costar. El bicho lo tiene crudo, porque yo no me voy a rendir. Para cabezota yo, no se vaya a creer que voy a dar mi brazo a torcer. Se ha encaprichado en dejarme lisiado y no hay manera, etc.

- Humorismo a través de paremias adaptadas.

Menudas dos patas para un banco (persona que por necesidad deambula con muletas). En el país de los ciegos, el tuerto es el rey (persona que ha perdido un ojo). Vísteme despacio que ruedo deprisa (persona que no puede vestirse), etc.

- Simulación de relaciones sentimentales a través del humor metafórico.

Me ha cogido interés y no me suelta por nada del mundo. Si esto sigue así le voy a dar plantón. Hoy me tiene disgustado, se pensará que puedo estar así todo el día, etc.

- Chascarrillos sobre la muerte, el tiempo restante y la jocosa decepción que esta (la muerte personificada) se va a llevar cuando vea lo que reclama.

Pues ya ves tú, al final va a salir robado, porque yo tengo poco que ofrecer. No creo que le vaya a dar para un guiso siquiera, a lo más para un caldo, solo tengo hueso. Me van a tener que hacer la caja redonda (persona con una gran desviación de columna). El día que me muera me van a tener que meter como una pieza de Tetris para enterrarme (persona con deformidad en tronco y/o extremidades), etc.

- Puesta en énfasis del hándicap como recurso humorístico en dicho contexto.

No sé para qué corre tanto, si a mí se me coge con una zancada (persona con reducción de movilidad en las piernas). Me caí al suelo y me tuvieron que echar más de una mano (persona a la que le falta una mano). No te preocupes, yo te vigilo las toallas y al niño que no se te ahogue (persona con estrabismo), etc.

5. Trabajo de campo: ejemplos recopilados en el intérvalo 2006 - 2017 en las instalaciones de los Hospitales Universitarios Virgen del Rocío y Virgen de Valme - Sevilla, de los cuales gran parte aparecen recogidos en Portillo-Fernández (2016). El corpus analizado se ha generado a partir de testimonios en conversaciones espontáneas, no estando sujeto a cuestionarios tipo, sino al estado del paciente y al contexto del momento. 
Este modelo de $H D D$ ha proliferado en la red, creándose incluso comunidades en Facebook y Twitter como «Humor Discapacitado» ${ }^{6}$, entre otros, en funcionamiento desde 2012 y con más de 25.000 seguidores, parte de ellos personas con discapacidad. Un hecho como este revela que la perspectiva del colectivo aboga por el sentido del humor como terapia para combatir sus limitaciones y ser feliz. Sin embargo, como ya hemos comentado en el apartado anterior, los límites del humorismo sobre discapacidad son debatidos y muchas veces no comprendidos como expresiones cómicas.

Independientemente del modo en que el humorismo refleje el buen humor de las personas con discapacidad y de las que las rodean, estamos asistiendo a un cambio de paradigma que ha generalizado el uso del humor como instrumento terapéutico.

Aunque por suerte, en la mayoría de los casos la discapacidad no conlleva efectos letales, como ocurre con algunas enfermedades que acaban con la vida, la estable o progresiva incapacitación del paciente puede ocasionar un cambio drástico de perspectiva vital, sobre todo si la discapacidad no es crónica. Una versión del humorismo, más relacionada con la enfermedad que con la discapacidad, la encontramos en los denominados «humorantes» (Coppin y Gaspard, 2017). La expresión humorante hace referencia al humor crudo que desarrollan algunos pacientes agonizantes como respuesta a la perplejidad de su situación. En menor grado, y siguiendo la estela de citada obra de Rodríguez Idígoras (2002), estudios más actuales como el de Sánchez et al. (2016) refuerzan el valor del humor como estrategia para afrontar el dolor crónico.

La aplicación del sentido del humor como estrategia intencionada para mejorar el bienestar emocional de las personas con discapacidad intelectual apenas si se ha intentado; no obstante, en el horizonte aparecen signos alentadores (Paredes Gómez, 2008: 214). Para establecer mecanismos humorísticos que mejoraran la calidad de vida de personas con discapacidad intelectual habría que tener más información sobre el entrenamiento para apreciar lo humorístico y en qué situaciones debe ser utilizado por los profesionales para mejorar el trato y la efectividad de los apoyos (Paredes Gómez, 2008: 215). Investigaciones posteriores como la de Paredes y Flores (2014) demuestran que literatura de humor popular adaptada en forma de textos sencillos y/o acompañados de dibujos, aumenta la calidad de vida de estas personas.

\section{La cromática del humor sobre discapacidad y su impacto mediático}

Albrecht (1999) ya planteó hace casi veinte años la paradoja del humor en la discapacidad, explicando que se trataba de una especie de anclaje entre la tragedia y la comedia que daba sentido a la propia experiencia de la discapacidad. La extensa producción literaria y académica acerca del humor negro no es unánime a la hora de establecer los límites de este, principalmente por haberse definido como un humor sin límites que funciona como catalizador frente a la desgracia. El humor negro ${ }^{7}$ es definido por la RAE como el humorismo que se ejerce a propósito de cosas que suscitarían, contempladas desde otra perspectiva, piedad, terror, lástima o emociones parecidas.

6. Véase: <https://www.facebook.com/HumorDiscapacitado/> y <https://twitter.com/humordisca>.

7. Real Academia Española. (s.f.). En Diccionario de la lengua española (23a ed.). Recuperado de http://dle.rae.es/. 
Sin embargo, ¿hasta qué punto tiene sentido de hablar de humor negro en discapacidad cuando el humorismo tiene su origen en la persona con discapacidad? Nos referimos al ya descrito $H D D$, un humorismo que precisamente surge de la necesidad de relativizar las circunstancias negativas que vive esa persona. El hecho de jugar y frivolizar sobre temas delicados y truculentos hace que muchas personas entiendan el humor absurdo como un abuso intelectual del indefenso con intención de hacer humor (Campos y Riaño, 2015). No obstante, el grado de corrección moral es el que funciona como autocensura, como auténtico límite del humorismo; ya que el afectado es quien decide, en última instancia, si le ofende o le hace gracia.

En este punto, es recomendable recordar a McLuhan $(1964,1995)$ cuando enunció su famoso aforismo «el medio es el mensaje» y años más tarde añadió que "el usuario es el contenido». La relación entre los elementos que conforman el flujo comunicativo, contexto incluido por supuesto, es la que determina el sentido del mensaje. De hecho, no hay mensaje con sentido hasta que el receptor extrae el significado de los estímulos recibidos. Darío Adanti, cofundador de la revista satírica Mongolia y colaborador de El Jueves, explicaba en su artículo «Ni puta gracia (sobre los límites del humor y su contexto)» que el humor es como el sadomasoquismo, un juego entre partes que aceptan jugar a ese juego y que lo que debe tener límites no es el humor sino el cuándo y el dónde de la representación del humor como acto. Esto implicaría un factor decisivo en la construcción del sentido del humorismo, el destinatario, la persona a la que hiere de forma consentida o no. Al contexto, en su sentido más laxo, entendido como las circunstancias de tiempo y espacio, factores sociales, culturales y cognitivos relativos a los participantes del intercambio comunicativo; hay que sumarle al hablar de discapacidad el contexto vital del emisor, como hemos comentado en el apartado 3. «Un chiste sobre el holocausto contado por una víctima del holocausto significa una cosa, el mismo chiste contado por un nazi, significa otra» (Adanti, 2015).

¿Cómo afecta lo expuesto al $H D D$ ? Precisamente este caso sería otro ejemplo idóneo para ilustrar las propuestas de McLuhan «el usuario es el contenido» $\mathrm{y}$ «el medio es el mensaje», porque el contenido y el mensaje del $H D D$ están basados en el propio usuario (emisor y destinatario/objetivo, a la vez) y su contexto (tanto su entorno, como sus circunstancias vitales).

Psicólogos especializados en discapacidad afirman que el humor es una forma de poder interpretar diferentes situaciones y contextos de un modo alegre. Esta capacidad es una forma de inteligencia emocional, la cual es importante para lograr una mejor adaptación, mayor integración, y una normalización (Luis, 2015). Uno de los casos más significativos y mediáticos de HDD es el nadador paralímpico Xavier Torres, que en su perfil de Twitter $^{8}$ hace alarde de su buen humor.

- Venga! Lo voy a hacer porque no puedo evitarlo 2 Aquí Fermín Cacho y un cacho de Xavi (3) $-31 / 10 / 17$.

- El «equipaje de mano» ya en su sitio 9 @ 9 Paralimpicos \#RoadToRio \#swimming \#coach - 03/09/16.

- La siesta de hoy se me ha ido de las manos... Bueno, ya sabéis de las manos... - 05/08/16.

- Como nadador, tengo que confesar que hay algo que odio de la natación. En toda mi carrera nunca logré hacer pie en la piscina $19-30 / 06 / 16$.

8. Véase: <https://twitter.com/xavi_torres>. 
- Eh! Un momento! Lo pienso sólo yo o el trofeo de Messi se parece sospechosamente a mí?? Exijo una explicación! -27/08/15.

- Os cuento un secreto? El niño del chiste de «mira papá, sin manos». Sí, sí, ese mismo... pues era yo! \#quedadicho $-26 / 10 / 15$.

El $H D D$ mediático no solo ha llegado al ámbito deportivo, se suman a este monologuistas con discapacidad como el Langui, cómicos / youtubers como el estadounidense Zach Anner, políticos como Pablo Echenique $^{9}$, entre otros. En el estudio sobre el sentido del humor y discapacidad presentado por Abadi (2009: 6) los participantes opinaron que el sentido del humor puede ser un elemento importante en la inclusión de las personas con discapacidad, y que muchas veces esto depende de la actitud que ellos mismos tomen ante la vida. El colectivo de personas con discapacidad que formó parte de la investigación consideró de manera unánime el humor como catalizador de emociones negativas, como medio de aprendizaje, como un remedio natural contra el estrés, y como un medio infalible de comunicación, ideas registradas años antes por Rieger (2004).

El laureado largometraje de Javier Fesser, Campeones (2018), que cuenta la historia de un entrenador profesional de baloncesto en medio de una crisis personal al entrenar a un equipo compuesto por personas con discapacidad intelectual, es una magnífica e inteligente muestra actual de cómo la diversidad funcional es completamente compatible con el humorismo. Chaplin ponía como condición de posibilidad del humor la necesidad de que el chiste estuviera a favor del débil y no del fuerte. [...] Comte-Sponville afirmaba que lo importante es que la risa agregue algo de alegría, algo de dulzura o de ligereza a la miseria del mundo, y no más odio, sufrimiento o desprecio. Se puede bromear con todo, pero no de cualquier manera (Kreimer 2002: 168). Y, actualizando la afirmación de Chaplin, diríamos que el humor siempre debe estar a favor de un mundo inclusivo y comprensivo, a favor del «reirse con», no del «reirse de».

\section{Conclusiones}

La obsolescencia del lenguaje, causada por múltiples motivos entre los que destacan el desuso por parte de la comunidad hablante, la sustitución por nuevos términos más adaptados a las circunstancias y a las ideas que deben representar, o la desaparición de la realidad a la que aludían, entre otros, es un fenómeno inevitable debido al carácter orgánico de este. El léxico relacionado con la discapacidad no es una excepción y la evolución de este resulta decisiva para entender la corrección o incorrección política y el humorismo desarrollado a su alrededor. En nuestro estudio sobre los límites del humor, al analizar el sentido y el uso que se les da a las palabras relacionadas con la discapacidad y su progresiva edulcoración para eliminar connotaciones peyorativas, prestamos atención al grado de relación que el emisor tenga con la discapacidad, al contexto en el que se produzca la emisión y a la intención comunicativa del locutor.

9. Véase: Langui_Oficial : <https://twitter.com/langui_oficial>, Zach Anner: <https://twitter.com/zachanner> y Pablo Echenique : <https://twitter. com/pniques. 
En relación con el primer factor, el grado de relación que el emisor tenga con la discapacidad, distinguimos tres enfoques del humorismo en discapacidad: 1) El humorismo relacionado con la discapacidad, procedente de personas con discapacidad - [HDD]. 2) El humorismo relacionado con la discapacidad, procedente de personas sin discapacidad o de personas que no tienen vinculación directa con la discapacidad (familiares o amigos íntimos con discapacidad) - [HDnD]. 3) El humorismo relacionado con la discapacidad, procedente de personas sin discapacidad que tienen vinculación directa con la discapacidad (familiares o amigos íntimos con discapacidad) - [HDvD]. Cada uno de estos enfoques establece niveles prácticos de uso (por parte del emisor) y de tolerancia (por parte de la comunidad hablante) en el humorismo sobre discapacidad; igual que el lugar, el momento y el medio de difusión, que resultan decisivos en el establecimiento de los límites morales.

Influido decisivamente por estos motivos, el humor negro, que tenía como objeto los defectos físicos, intelectuales o sensoriales ha desaparecido paulatinamente de los espectáculos cómicos dando paso a un humor monologado en primera persona basado en supuestas experiencias propias. El HDnD ha quedado obsoleto dando el relevo a un nuevo modelo humorístico HDD y HDvD sensible y compatible con la discapacidad.

En el plano social, a pie de calle, también ha disminuido sensiblemente el uso de las denominaciones relacionadas con la discapacidad y sus diversos grados de afectación para insultar a personas sin discapacidad. Este importante avance educacional ha sido gracias al esfuerzo de los educadores en valores, a la visibilización normalizada de las personas con discapacidad en los medios de comunicación, a los planes estatales de ayuda e integración, a las asociaciones de afectados y familiares, así como a la mayor apertura y movilidad social; aumentando el rechazo social y la reserva a usarlas de forma grosera e insultante.

Se registra en el trabajo de campo realizado sobre $H D D$ el debilitamiento del problema a través de la parodia y la ridiculización, la frecuente personificación de la enfermedad y/o discapacidad para poder insultarla y echarse apuestas con ella, el humorismo a través de paremias adaptadas, la simulación de relaciones sentimentales a través del humor metafórico, la aparición de chascarrillos sobre la muerte, el tiempo restante y la jocosa decepción que esta (la muerte personificada) se va a llevar cuando vea lo que reclama y la puesta en énfasis del hándicap como recurso humorístico en dicho contexto.

Por otra parte, la proliferación de plataformas virtuales y perfiles en las redes sociales sobre «humor discapacitado" está produciendo un beneficioso viraje en la imagen del colectivo, en el que se relativiza la discapacidad y sirve de catalizador de las emociones negativas. Del mismo modo, reparamos en una película que presenta con inteligencia la realidad de las personas discapacitadas, una demostración de que es posible el humorismo sobre discapacidad sin cargas negativas sobre sus protagonistas. Se puede hacer humor con personas con discapacidad sin que este sea a su costa.

Por último, es importante destacar que no podemos hablar de humor negro al referirnos al $H D D$, sino de una forma de inteligencia emocional para lograr una mejor adaptación, mayor integración y la normalización. Son muchas personas con discapacidad, dedicadas a diferentes ámbitos, las que utilizan el «humor discapacitado» como herramienta para mejorar la percepción de su contexto vital. 
Referencias bibliográficas

Abadi, M.C. (2009): Sentido del humor y discapacidad: dos elementos que deben ir juntos y formar parte de la educación, pero muy pocos se atreven a unir (en línea). <http://www.discapacidadonline.com/wp-content/ uploads/2013/01/sentido-del-humor-discapacidad.pdf>, acceso 5 de septiembre de 2017.

Acevedo, E. (1972): Los españolitos y el humor. Madrid: Editora Nacional.

Adanti, D. (2015): Ni puta gracia (sobre los límites del humor y su contexto) (en línea). <http://www.eldiario.es/zonacritica/puta-gracia-limites-humor-contexto_6_399020106.html>, acceso 19 de septiembre de 2017.

Albrecht, G. L. (1999): “Disability humor: What's in a joke?”. Body \& Society, 4 (5): 67-74.

Barragán, A. R. y Morales, C. I. (2014): «Psicología de las emociones positivas: generalidades y beneficios». Enseñanza e investigación en Psicología, 19 (1): 103-118.

Bolinger, D. (1980): Language: The Loaded Weapon. The Use and Abuse of Language Today. Michigan University: Longman.

Brown, G. y Yule G. (1993): Análisis del discurso. Madrid: Visor Libros.

Campos, P. y Riaño, P.H. (2015): ¿Tiene límites el humor negro? (en línea). <https://www.elconfidencial.com/cultura/2015-06-16/tiene-limites-el-humor-negro_886805/>, acceso 2 de noviembre de 2017.

Carbelo, B. (2008): El humor en la relación con el paciente: una guía para profesionales de la salud. Barcelona: Masson.

Carbelo, B. y Jáuregui, E. (2006): «Emociones positivas: humor positivo». Papeles del psicólogo, 27 (1): $18-30$.

Chazenbalk, L. (2006): «El valor del humor en el proceso psicoterapéutico». Psicodebate, 6: 73-84.

Coppin, M. y Gaspard, J.L. (2017): «El humor negro frente a la muerte». Desde el jardín de Freud: revista de psicoanálisis, 17: 149-160.

España. Real Decreto Legislativo 1/2013, de 29 de noviembre, por el que se aprueba el Texto Refundido de la Ley General de derechos de las personas con discapacidad y de su inclusión social, Boletín Oficial del Estado, 3 de diciembre de 2013, núm. 289, pp. 95635-95673.

Fuentes Rodríguez, C. (2000): Lingüística pragmática y análisis del discurso. Madrid: Arco/Libros.

Galán, L. (2017): «Sinhogarismo» y «monomarental» (en línea). <https://elpais.com/elpais/2017/11/11/opinion/1510392938_348606.html>, acceso 31 de octubre de 2017.

Garanto Alós, J. (1983): Psicología del humor. Barcelona: Herder.

Jáuregui, E. (2008): «Tomarse el humor en serio: aplicaciones positivas de la risa y del humor», en Vázquez y Hervás (coord.): Psicología positiva aplicada. [s.I.] : Desclée de Brouwer.

Jordán de Urríes, F. y Verdugo, M. (2015): Mirando a la discapacidad con humor. Salamanca: Instituto Universitario de Integración en la Comunidad.

Kreimer, R. (2002): Artes del buen vivir. Filosofía para la vida cotidiana. Buenos Aires: Anarres.

Luis, C. (2015): ¿Se puede bromear con la discapacidad? (en línea). <http://www.elmundo.es/enredados/2015/09 /28/560915fdca4741ea6e8b4581.html>, acceso 24 de octubre de 2017. 
Martin, R. A. (2008): Psicología del humor: un enfoque integrador. Madrid: Orión.

McLuhan, M. et al. (1995): Essential McLuhan. Nueva York: Basic Books.

McLuhan, M. (2003): Understanding Media: The Extensions of Man. Corte Madera (Canadá): Gingko Press - [Original: 1964].

Organización de las Naciones Unidas, ONU (2006): Convención Internacional sobre los Derechos de las Personas con Discapacidad. Nueva York: ONU.

Paredes Gómez, D. (2008): «La experiencia del humor en personas con discapacidad intelectual». Electronic journal of research in educational psycology, 14 (6): 201-218.

Paredes Gómez, D. y Flores Nieto, A. (2014): "Promoviendo el sentido del humor en las personas adultas con discapacidad intelectual y del desarrollo". Revista Española de Discapacidad, 2 (2): 219-231.

Portillo-Fernández, J. (2016): El testamento vital del profesor Wicket. Madrid: Loquenoexiste.

Rieger, A. (2004): «Explorations of the functions of humor and other types of fun among families of children with disabilities». Research \& Practice for Persons with Severe Disabilities, 29 (3): 194 -209.

Rodríguez Idígoras, A. (ed.) (2002): El valor terapéutico del humor. Bilbao: Desclée De Brouwer.

Romañach, J. y Lobato, M. (2005): Diversidad funcional, nuevo término para la lucha por la dignidad en la diversidad del ser humano (en línea). <http://forovidaindependiente.org/wp-content/uploads/diversidad_funcional. pdf $>$, acceso 24 de octubre de 2017.

Sánchez, S. et al. (2016): «El humor como estrategia de afrontamiento del dolor crónico». Revista de psicología de la salud, 1 (4): 93-129.

Siruana, J. C. (2014): «Ética del humor y diversidad cultural». Dilemata, año 6, 15: 215-231.

Van Dijk, T. A. (2000): «El discurso como interacción en la sociedad» en: Discurso como interacción social: Estudios sobre el discurso. Barcelona: Gedisa.

Van Dijk, T. A. (1980): Texto y contexto. Madrid: Cátedra. 